\title{
Characterization of European wind speed variability using weather regimes
}

\author{
Nicola Cortesi ${ }^{1}$ (D) $\cdot$ Verónica Torralba $^{1} \cdot$ Nube González-Reviriego $^{1} \cdot$ Albert Soret $^{1} \cdot$ Francisco J. Doblas-Reyes $^{1,2}$
}

Received: 9 November 2018 / Accepted: 28 May 2019 / Published online: 4 June 2019

(c) The Author(s) 2019

\begin{abstract}
The aim of this paper is threefold. Firstly, to present a representative set of large-scale weather regimes for each month of the year over the Euro-Atlantic region and compare them amongst three commonly employed global reanalyses. Secondly, to measure the impact of the weather regimes on near-surface wind speed variability. Lastly, to validate the regime's ability to reconstruct monthly wind speed anomalies. Wind speed reconstruction provides critical information on the role of weather regimes as source of predictability of wind speed, by identifying areas where wind is poorly or highly influenced by weather regimes as a whole. Conclusions are extracted about the adequacy of weather regimes to characterize local wind speed variability over Europe.
\end{abstract}

Keywords Weather regimes $\cdot$ Sources of predictability $\cdot$ Reanalysis intercomparison $\cdot$ Wind speed $\cdot$ Wind energy $\cdot$ Climate services

\section{Introduction}

Synoptic climatology traditionally classifies the complex dynamics of large-scale atmospheric circulation in a few recurrent and quasi-stationary (persistent) patterns called 'weather regimes' (WRs). They result from the interaction between synoptic-scale and planetary-scale atmospheric waves (Ghil and Robertson 2002), as the atmosphere tends to persist in the same WR for 3-7 days before transitioning to a different one (Fereday 2017). WRs were extensively used to investigate atmospheric variability (Philipp et al. 2010; Hannachi et al. 2017), particularly at mid-latitudes in the Euro-Atlantic region (Yiou and Nogaj 2004; Peña-Angulo et al. 2016; Raymond et al. 2018), North America (Coleman

Electronic supplementary material The online version of this article (https://doi.org/10.1007/s00382-019-04839-5) contains supplementary material, which is available to authorized users.

Nicola Cortesi

nicola.cortesi@bsc.es

1 Earth Sciences Department, Barcelona Supercomputing Center, Carrer Jordi Girona 31, Barcelona, Spain

2 Institució Catalana de Recerca i Estudis Avançats, Pg. Lluís Companys 23, Barcelona, Spain and Rogers 2007; Roller et al. 2016; Vigaud et al. 2018) and Pacific (Wilson et al. 2013; Lorrey and Fauchereau 2018).

Different assumptions should be considered in the assessment of the WRs. The optimal number of WRs to describe the atmospheric circulation strongly depends on the variable(s), classification method, spatial domain and period chosen, and often vary from 2 to $10 \mathrm{WRs}$ (Casado et al. 2009). WRs are usually defined by classifying a circulation variable such as geopotential height, sea level pressure (SLP) and/or wind components. Most of the studies on WRs in the Euro-Atlantic region focus on the winter season (Fil and Dubus 2005; Ferranti and Corti 2011; Vrac et al. 2014; Ferranti et al. 2015; Thornton et al. 2017), because in this period WRs are more stable in time (more persistent), and have a stronger influence on local climate (Cassou et al. 2004).

In literature, four optimal wintertime (DJF) WRs are identified in the Euro-Atlantic region (Yiou et al. 2008; Cassou et al. 2004; Ferranti et al. 2015). Two of them are consistent with the spatial patterns of the two opposite phases of the North Atlantic Oscillation or NAO (Trigo et al. 2004; Hurrell and Deser 2009), and are therefore called "NAO+" and "NAO-" regimes. A third WR is called "Blocking" (BL), since it shows a strong and positive anomaly centred over Scandinavia and a weaker negative anomaly over the Atlantic Ocean, similar to the atmospheric flow during blocking 
events in Europe (Tyrlis and Hoskins 2008). The fourth WR is called "Atlantic Ridge" (AR), as it is represented by a positive anomaly over the Atlantic Ocean and a negative one over Scandinavia, similar to the negative phase of the East Atlantic pattern (Barnston and Livezey 1987).

WRs classifications can also be defined in summer (Cassou et al. 2005), albeit with different patterns from winter and usually employing geopotential height instead of SLP to reduce spatial noise (Guemas et al. 2010; Quesada et al. 2012). In spring and autumn, the higher spatial variability of the atmospheric circulation makes more difficult to identify a set of persistent WRs (Yiou et al. 2008).

Studies comparing how different reanalyses characterize large-scale atmospheric circulation are typically restricted to regions with few observations, such as the tropics or the Arctic (Kumar et al. 2013; Nygård et al. 2016). Well-observed regions, such as the extratropical region of the Northern Hemisphere, are less studied (Carvalho et al. 2014), since it is assumed that differences between reanalyses are small or negligible (Dell'Aquila et al. 2016). Recently, a comprehensive reanalysis comparison of WRs over Europe in winter was published by Stryhal and Huth (2017).

WRs are often classified at seasonal or annual time scale, using all the days corresponding to a specific season or year (Neal et al. 2016; Grams et al. 2017; Fereday 2017). Plenty of classifications are available in literature and no one was found to be superior to the others (see the comprehensive review of Hannachi et al. 2017)

Many users in various sectors of the society (renewable energy, agriculture, insurance, health, etc.) ask for precise regime classifications, tailored to their needs. They are interested in knowing and understanding the impact of WRs on variables or indicators related to their activities, which can vary substantially from one month to the next. Changes in WR monthly frequencies, in fact, often determine most part of the variation of monthly anomalies of climate variables such as sea surface temperature (Polo et al. 2013), precipitation (Beck et al. 2007) or wind speed (Couto et al. 2015) over the Euro-Atlantic region. For this reason, WRs can be useful in many wind energy applications. Exceptions can be found in those areas or periods in which large-scale circulation is less related to local winds, such as in regions with complex orography (Salameh et al. 2009) or in the summer season (Dünkeloh and Jacobeit 2003).

Another approach to characterize the variability of large-scale atmospheric circulation is represented by the leading Empirical Orthogonal Functions (EOFs) of any variable describing the large scale flow, like geopotential height or sea level pressure. Like WRs, also the EOFs refer to recurring and persisting large-scale circulation patterns (Wallace and Gutzler 1981; Hurrell 1996; Tippett et al. 2008; Gonzalez-Reviriego et al. 2015). However, they typically last for several weeks or months and span vaster geographical area than WRs (Thompson and Wallace 1998). WRs can also be defined by clustering the leading EOFs (Fereday et al. 2008). Moreover, the EOFs are symmetric, as the centres of action of both the positive and negative phases are in the same location but with opposite sign, while the centres of the WRs are in different positions, as the k-means analysis seeks the most steady states (Barrier et al. 2014). Finally, WRs can also be defined by clustering the leading EOFs (Fereday et al. 2008); in this case, WRs simply depict the interplay between the EOFs phases (Zubiate et al. 2017).

The ongoing interest of the scientific community in understanding the mechanisms driving monthly wind speed variability resulted in the publication of several studies. Couto et al. (2015) detected a strong association between some WRs and sudden variations of the wind power production in Portugal, aiming at developing a diagnostic warning system. Kempton et al. (2010) analysed the main synoptic systems transiting the U.S East Coast to determine the optimal configuration of offshore wind sites, which minimize wind power fluctuations. Grams et al. (2017) performed a similar study for the European region, exploring in detail the relationship between wind power generation and WRs defined at annual time scale, demonstrating that Euro-Atlantic WRs determine important local wind electricity surpluses and deficits, which can last up to a few weeks, seriously limiting the adoption of wind energy as a major source of power generation. Finally, Zubiate et al. (2017) measured the sensitivity of winter wind speed to the three leading EOFs in the EuroAtlantic region, identifying where wind speed variability is influenced by the leading EOFs.

Unlike many previous studies, the main goal of this paper is not that of identifying a small set of WRs for the EuroAtlantic region with almost constant spatial patterns through all the year. Instead, it consists in generating a representative set of WRs to study their impact on 10-m wind speed, month by month. This work also tries to identify regions that, due to their location and to their link with WRs, might play a strategic role in future renewable energy generation. It complements the study of Grams et al. (2017), by employing a monthly-based WR classification, and with a different number of WRs and reanalysis choice.

The paper is organized as follows. Section 2 introduces the three reanalysis datasets employed and describes the methodology to generate the monthly WRs. Section 3 exhibits the main results of the study in terms of WRs patterns and frequencies for different reanalyses, their impact on wind speed and their skill in reconstructing wind speed. The optimal number of WRs, the main differences between WR classifications in literature and the choice of the more appropriate reanalysis for operational products are discussed in Sect. 4. Finally, conclusions are drawn in Sect. 5. 


\section{Data and methodology}

\subsection{Data and pre-processing}

This study employs daily-mean fields of SLP and 10-m wind speed from three gridded global reanalysis datasets: JRA-55 (Kobayashi et al. 2015), ERA-Interim (Dee et al. 2011) and NCEP-NCAR Reanalysis 1 (Kalnay et al. 1996, henceforth NCEP). Each dataset has a different spatial resolution: $1.25^{\circ}$ (JRA-55), $0.75^{\circ}$ (ERA-Interim) and $2.5^{\circ}$ (NCEP). For a detailed characterization of $10-\mathrm{m}$ wind speed, see Marcos et al. (2018). For a comparison of the uncertainty affecting near-surface wind speed trends from different reanalyses, see Torralba et al. (2017b). Usually, $100-\mathrm{m}$ wind speed is preferred to $10-\mathrm{m}$ for wind power studies, as it corresponds to the height of a typical wind turbine. However, neither of the three chosen global reanalysis provides wind data directly at $100-\mathrm{m}$ height. Wind data at this height can still be inferred by interpolating wind reanalysis data at nearby levels, but these approaches require stability assumptions. For simplicity, this work is based on 10-m wind speed.

Energy companies are often interested in knowing the observed daily sequence of weather regimes in the region surrounding their wind farms for the previous month, along with the impact of each regime on wind speed, to be able to attribute the months with a lower than normal energy production to atmospheric dynamics, rather than to human causes. In this case, reanalysis data need to be updated frequently, to be able to provide the product to the company within the shortest period possible, typically once for month. Since ERA-Interim reanalysis is updated once every 3-4 months, it is not possible to develop a monthly product based on the data of the previous month, but only on the data of 3-4 months before the current one, which is usually too late to be useful to the companies.

As ERA-Interim is not delivered in real-time, the alternatives for the development of tailored products for the users, consist in completing the ERA-Interim sample with the ECMWF operational analysis, which is available in near real time, or in using a different reanalysis like JRA55 or NCEP, both available with a delay of a few days only. However, the NCEP dataset is coarser than the JRA-55 reanalysis $\left(2.5^{\circ}\right.$ instead of $\left.1.25^{\circ}\right)$, so the latter dataset is usually preferred. For this reason, in this work only the results for the JRA-55 are shown, along with the comparison with the results for the other two reanalyses. Individual results for ERA-Interim and NCEP can be found in the supplementary material.

The original resolution of the reanalyses was employed for all analyses, including $k$-means. Only two measures are based on interpolated data: the spatial correlations between regime anomalies ("pattern correlations") and the ones between wind speed anomalies, to be able to compare the WR patterns between reanalyses with different resolutions. For this purpose, a bilinear interpolation of ERAInterim and JRA-55 was performed to the same resolution of NCEP data, the one with the lowest resolution $\left(2.5^{\circ}\right)$.

Data from 1981 to 2016 (36 years) for the Euro-Atlantic region $\left(27^{\circ} \mathrm{N}-81^{\circ} \mathrm{N}, 85.5^{\circ} \mathrm{W}-45^{\circ} \mathrm{E}\right)$ are used for classifying WRs. Daily-mean data were computed as an average of 6-h data (00, 06, 12 and 18 UTC). Daily anomalies for both SLP and 10-m wind speed were computed from the daily climatology of the respective dataset for the period 1981-2016. Anomalies were filtered with a LOESS polynomial regression with a degree of smoothing $\alpha=0.35$ optimized to remove the annual cycle and smooth out the short-term variability of the climatological estimates (Mahlstein et al. 2015). Before classifying the WRs, daily gridded SLP anomalies were weighted by the cosine of the latitude, in order to ensure equal area weighting at each grid point. Daily 10-m wind speed was used to measure the impact of the monthly WRs on wind.

\subsection{Weather regimes}

Several methodologies were developed for classifying WRs (Philipp et al. 2010). The most popular methods are based on non-linear clustering algorithms (Esteban et al. 2006; Fereday et al. 2008; Huth et al. 2008; Sanchez-Gomez et al. 2008; Dawson et al. 2012). Between all the clustering techniques, one of the most commonly employed in the literature is the k-means algorithm (Hartigan and Wong 1979), which was previously shown to be useful in identifying WRs (Robertson and Ghil 1999; Stahl et al. 2006; Boé et al. 2007).

The $k$-means algorithm was chosen in this study to obtain the monthly WRs classification of daily SLP anomalies over the Euro-Atlantic region. This algorithm minimizes the sum over all clusters of the within-cluster SLP variance $(V)$. Its main caveat is that the optimal number of clusters $k$ is not defined a priori. For this reason, the 'elbow criteria' was chosen for selecting the lowest number of clusters that minimize $V$ (Kodinariya and Makwana 2013). The optimal number of clusters is found when $V$ almost stops decreasing with the increase of $k$.

In this work, for each individual reanalysis and month of the year, a set of $k=4$ preferred WRs was generated by the $k$-means, corresponding to the more robust WR partition during winter months (Michelangeli et al. 1995). Due to the random process employed by the $k$-means cluster algorithm to identify the four optimal regime centres, the average monthly frequency of occurrence associated with each regime is not uniquely determined, but can vary of a few percent points when repeating the cluster analysis, because of the different position of the cluster centroids. SLP daily anomalies can also 
be filtered prior to the clustering to reduce their dimensions, by performing a principal component analysis (PCA, see Preisendorfer 1988). In this work, PCA filtering was not applied, to take into account also the more extreme SLP values.

The intercomparison of the WR classifications obtained from the chosen reanalyses was performed by different metrics. As each reanalysis is characterized by a slightly different daily WR time series, the first metric simply counts the number of days when the pair of chosen reanalyses associates different WRs to the same day (Stryhal and Huth 2017). This number was converted to a frequency by dividing it for the total number of days in the month considered during 1981-2016. The second and the third metrics measure respectively the spatial and temporal correlations between two correspondent WR patterns or WR monthly frequencies of pairs of reanalyses during 1981-2016.

The impact of a monthly WR on wind speed was measured by averaging the normalised wind speed anomalies for all days associated to a given WR and month. The normalised anomalies were obtained by dividing the daily wind speed anomalies by the climatological (monthly) average wind speed at a given point. This allows to better discern the impact over land, where wind speed is usually lower (in absolute value) than over the sea. A two-tailed Student's t-test was performed to assess the level of significance of the wind speed impact figures.

\subsection{Reconstructed wind speed by WRs}

To assess the effectiveness of the WRs in describing the 10-m wind speed, the mean daily wind speed was reconstructed. The reconstruction has been performed in a leave-one-out crossvalidation framework, in which the year to be reconstructed is excluded from the estimation of the observed impact of WRs on 10-m wind speed. Firstly, the observed impact $I_{r, m, y}$ (lat,lon) of a given regime $r$ in month $m$ and year $y$ on wind speed anomalies was measured by averaging the normalised wind speed anomalies $w_{r, m}(d$, lat, lon $)$ for all days $d$ associated to regime $r$ and month $m$ during 1981-2016, excluding year $y$ :

$I_{r, m, y}($ lat, lon $)=\sum_{d=1}^{N} \frac{1}{N} w_{r, m}(d$, lat, lon $)$,

with $N$ the number of days belonging to regime $r$ and month $m$ during $1981, \ldots, y-1, y+1, \ldots, 2016$.

Subsequently, WRs were employed to reconstruct the mean monthly wind speed anomaly $W_{m, y}($ lat, lon $)$ as the linear combination of the WR monthly impact $I_{r, m, y}$ and the WR frequencies:

$W_{m, y}($ lat, lon $)=\frac{1}{N_{m y}} \sum_{r=1}^{4} I_{r, m, y}($ lat, lon $) \cdot N_{r m y}$ being $N_{m y}$ the total number of days in month $m$ and year $y$ and $N_{r m y}$ the number of days belonging to the weather regime $r$, month $m$ and year $y$.

Finally, to assess the wind speed reconstruction, reconstructed mean monthly wind speed anomalies $W$ were compared to the observed ones over period 1981-2016 with four different metrics. The first one is the Pearson's correlation between the reconstructed and observed time series. It ranges from -1 to 1 , values closer to 1 indicate that the reconstructed wind speed is similar to the observed one. The second metric is the standard deviation ratio between the reconstructed and observed series and it ranges from 0 to 1 , with values close to 1 indicating a high similarity between the reconstructed and observed wind speeds variability. The third one is the Pearson's correlation between the reconstructed and observed time series of the 95th percentile of 6-h wind speed (read below), and it ranges from -1 to 1 . The last metric is the difference between the mean reconstructed and original wind speed time series, therefore a difference equal to zero represents a perfect agreement between the means of the reconstructed and original wind speed anomalies.

The 95th percentile of wind speed was obtained in crossvalidation with a similar approach to that used to reconstruct the time series of the mean wind speed. However, in order to improve the robustness of the measure of the 95th percentile thresholds, monthly anomalies were not reconstructed from the daily wind speed anomalies but from the 6-h wind speed anomalies. In this case, as the $k$-means clustering was still performed with daily SLP anomalies, all the four 6-h wind speed values within the same day were associated to the same daily WR.

\section{Results}

\subsection{Weather regime patterns and frequencies}

The spatial patterns of the SLP anomalies of the monthly WRs from JRA-55 for 1981-2016 are shown in Figs. 1 (for boreal winter and spring months) and 2 (for boreal summer and autumn months). SLP patterns are characterized by the number and position of their centroids, their shapes and intensity. A brief description of the spatial patterns for each month of the year is given in Table 1 of the supplementary material.

Even if WR patterns shown in Figs. 1 and 2 are classified at monthly scale, many of them resemble the four wintertime WR patterns $(\mathrm{NAO}+, \mathrm{NAO}-$, blocking and Atlantic ridge) described in the introduction. However, by adopting a monthly classification, regimes not present in the wintertime classification emerge too. Some examples are the third more frequent regime in January, characterized by a negative 

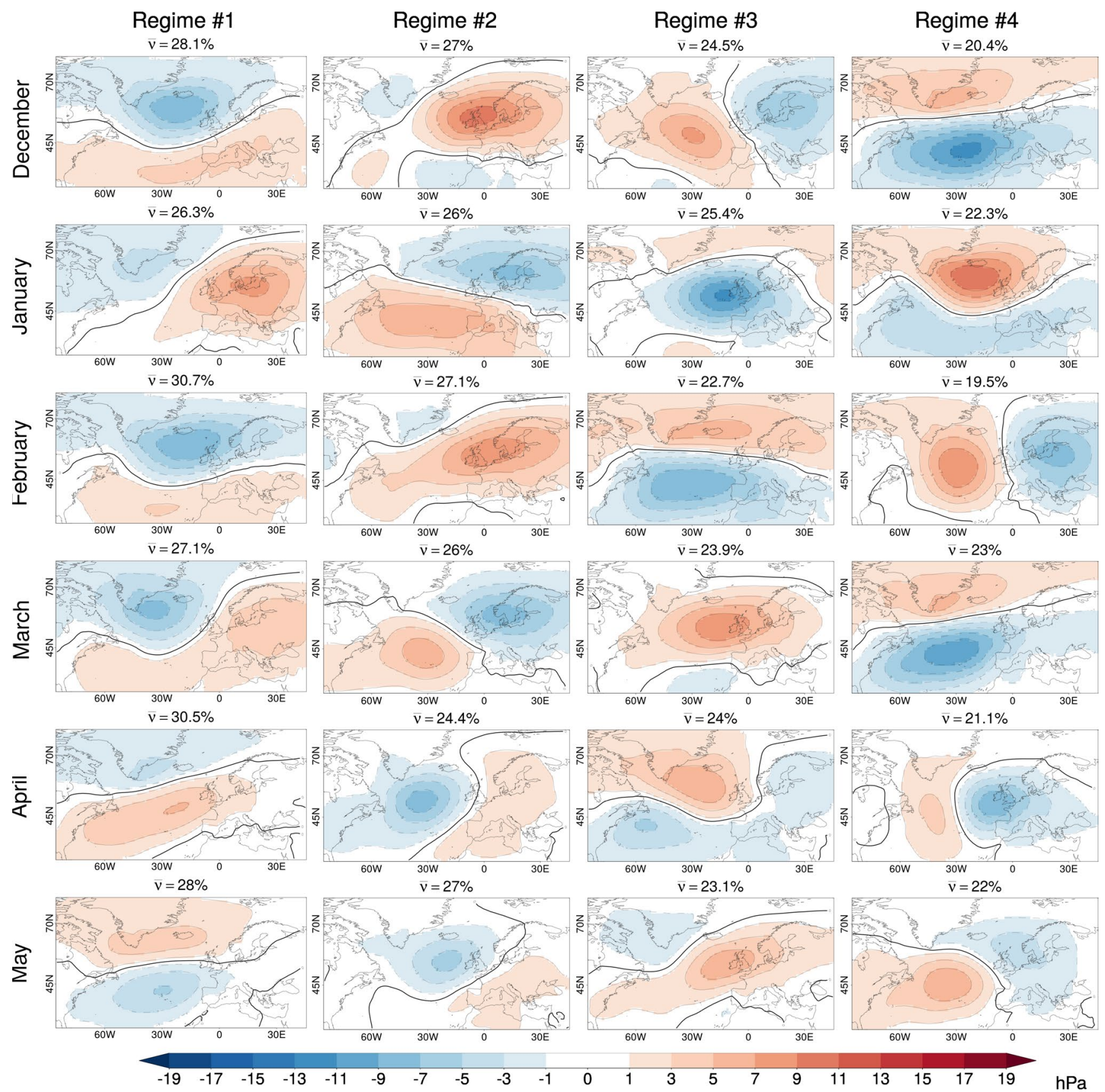

Fig. 1 Spatial SLP anomalies (hPa) of the four monthly regimes from December (top row) to May (bottom row) for the JRA-55 reanalysis. Regimes are shown, from left to right, in decreasing order of average

centroid to the west of UK (see Fig. 1), or the second more frequent regimes in April and May, both characterized by positive anomalies over continental Europe and negative ones over the Atlantic Ocean.

As a consequence of classifying each month separately, the WR patterns are usually quite different from those of the previous or following month. However, some spatial patterns are similar for many consecutive months, particularly from November to March, and only the order of monthly frequency (1981-2016), indicated by a \% above each map. Black lines separate regions with positive and negative anomalies

the WRs inside the sequence varies from one month to the next. For example, the patterns of the second more frequent WR in December are similar to those of the first more frequent WR in January and to those of the second more frequent WR in February. On the contrary, from April to October, the spatial patterns of the WRs are more variable from 1 month to the next. Many WR patterns in the winter months also resemble the annual WR patterns defined in Grams et al. (2017). 

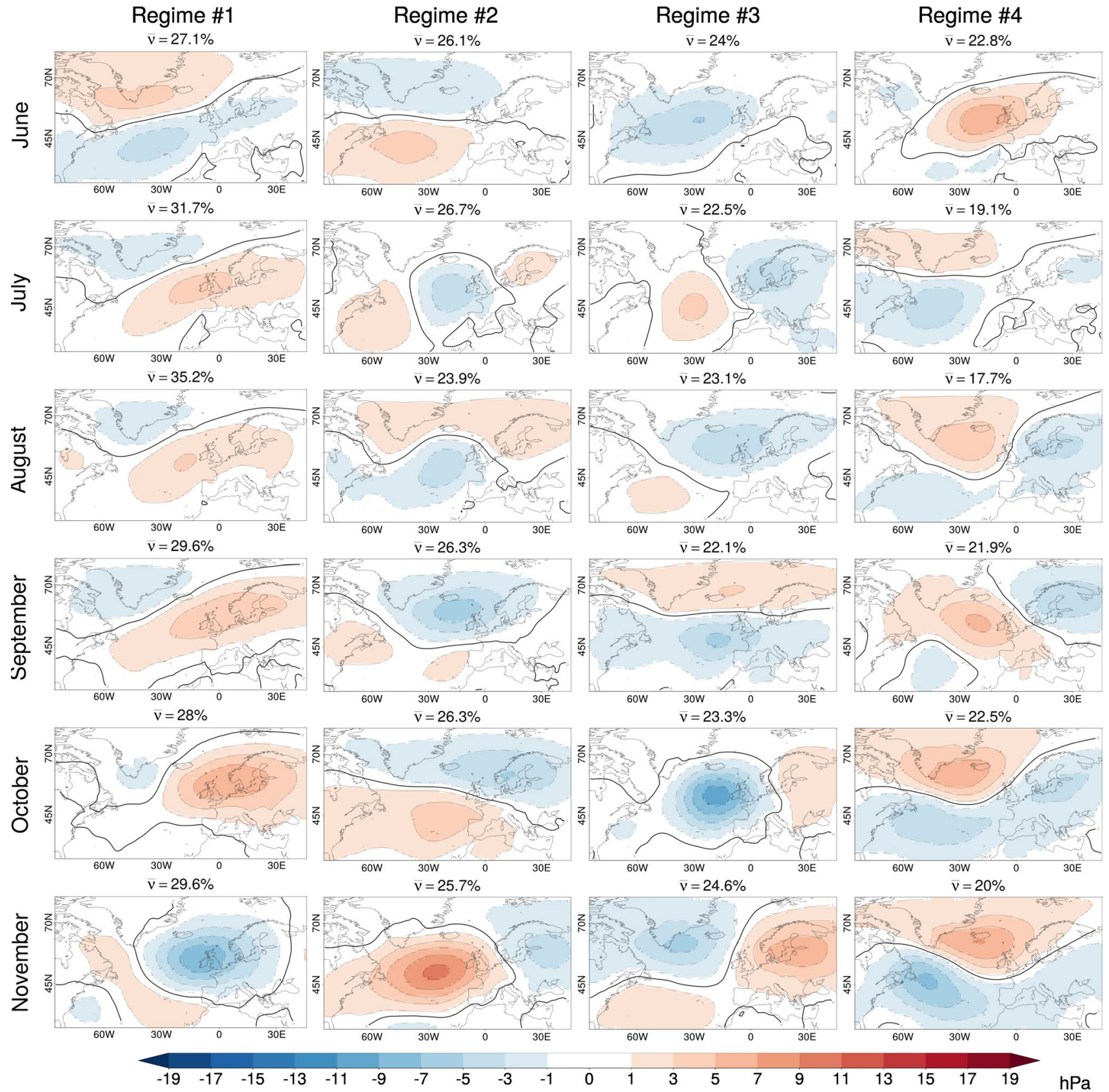

Fig. 2 As Fig. 1, but from June to November months

The average monthly frequency of occurrence of each of the four WRs ranges between 17 and 36\%. August is the month with the highest observed frequency range: $17.7-35.2 \%$ (Fig. 2). Summer months also have globally weaker patterns than other months (i.e: less intense ones, regardless the sign), as large-scale atmospheric circulation systems are less prominent in summer than in winter, as a consequence of the increased atmospheric convection during summer (Beck et al. 2007).
To quantify the differences between the WRs obtained for each reanalysis, the percentage of days classified with different WRs for pairs of reanalyses are shown in Table 1. The spatial and temporal correlations between two correspondent WR patterns (or WR monthly frequencies in case of temporal correlations) from pairs of different reanalyses are included in Tables 2 and 3 of the supplementary material.

Results suggest that the correspondence between the three reanalyses is very high and with highly significant 
correlations, with the exception of the months of April and July, when the largest differences are detected. Figures analogue to Figs. 1 and 2 but representing the SLP patterns derived from ERA-Interim and NCEP are shown in Figs. 1, 2, 3 and 4 of the supplementary material. Results are also consistent with the WR comparison between NCEP and JRA-55 performed by Stryhal and Huth (2017) in DJF, as in this season they also detected less than $8 \%$ of days classified with different WRs.

At a first glance, NCEP seems to be the reanalysis that differs the most from the others, particularly in April, when the $\%$ of different days raise to $37 \%$ for both the ERA-Interim and NCEP pair and the JRA-55 and NCEP pair (Table 1); in this month, the shape and position of the centroids of the second more frequent regime of NCEP (third row and second column in Fig. 3) are also profoundly different from those of any ERA-Interim or JRA-55 regime (first two rows in Fig. 3). However, these differences are not really due to NCEP data, but are introduced by the classification process: in fact, they disappear if the $k$-means clustering is performed after the spatial interpolation of the reanalysis (see Sect. 2), as it levels out the total number of grid points of the reanalysis. In this way, the clustering is applied to the same number of points and consequently in April the resulting regimes are almost identical for the three reanalysis (results not shown).

On the contrary, the high discrepancies observed in July for all the three pairs of reanalysis in Table 1 are invariant to a change of the order of the classification steps. Moreover, in July more than one regime exhibits different spatial patterns between the three reanalysis (see Figs. 2 and 4 of the supplementary material). During other months, the percentage of days belonging to a different WR between pairs of reanalysis is acceptable, as it doesn't exceed 3\% (Table 1) and both spatial and temporal correlations are significant and above $r \geq 0.98$ (Tables 2 and 3 of the supplementary material).
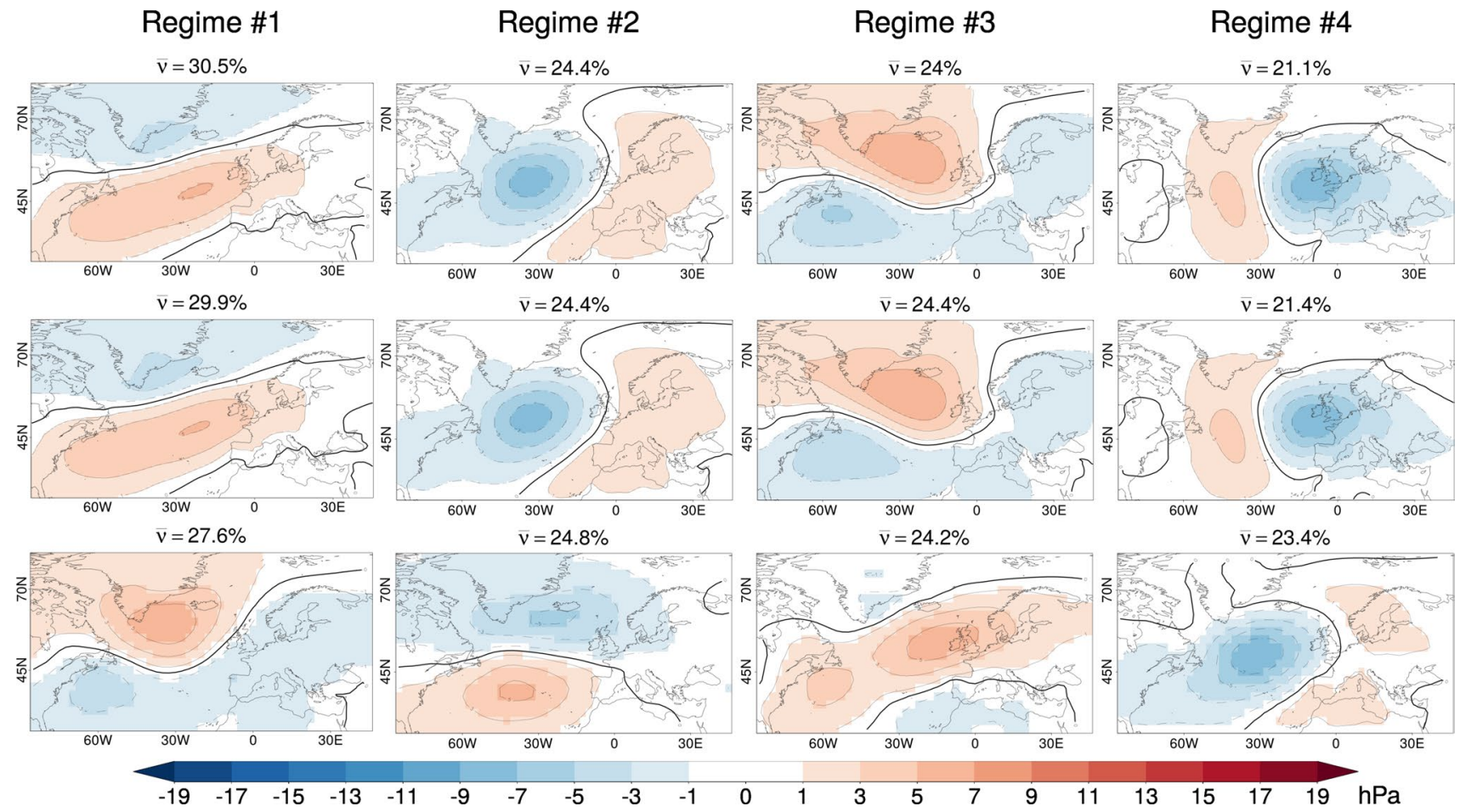

Fig. 3 Spatial SLP anomalies (hPa) of the four monthly regimes of April for JRA-55 reanalysis (top), ERA-Interim (centre) and NCEP (bottom). Regimes are shown, from left to right, in decreasing order of average monthly frequency (1981-2016), indicated by a \% above each map. Black lines separate regions with positive and negative anomalies
Table 1 Percentage of days classified with different WRs for pairs of different reanalyses during period 1981-2016

\begin{tabular}{lcccccccccccc}
\hline Reanalysis & Jan & Feb & Mar & Apr & May & Jun & Jul & Aug & Sep & Oct & Nov & Dec \\
\hline JRA-55 vs ERA-Interim & 0.9 & 1.3 & 0.1 & 1.7 & 1.2 & 1.3 & $\mathbf{3 0 . 7}$ & 0.8 & 2.1 & 1.0 & 0.6 & 1.4 \\
JRA-55 vs NCEP & 1.4 & 0.9 & 1.1 & $\mathbf{3 6 . 9}$ & 2.1 & 2.1 & $\mathbf{2 5 . 4}$ & 2.2 & 1.6 & 1.7 & 1.4 & 1.6 \\
ERA-Interim vs NCEP & 1.8 & 1.8 & 1.1 & $\mathbf{3 7 . 0}$ & 2.6 & 2.8 & $\mathbf{2 4 . 6}$ & 2.1 & 1.7 & 2.2 & 1.9 & 2.2 \\
\hline
\end{tabular}

Bold numbers show percentages higher than $3 \%$ 


\subsection{Regime impact on wind speed}

The assessment of the WRs on wind speed is focused on continental Europe and surrounding shores. The spatial patterns of the impact of the four monthly WRs on daily 10-m wind speed for JRA-55 are presented in Figs. 4 and 5. Impact maps for the other two reanalyses can be found in Figs. 5, 6,7 and 8 of the supplementary material, as well as a short description of the spatial patterns of each impact map for JRA-55 (Table 4 of the supplementary material).

Both ERA-Interim and NCEP present spatial patterns very similar to those of JRA-55 (apart the different resolution), except in April and July, due to the different patterns of the SLP anomalies described in Sect. 3.1 (see Fig. 3).

It is evident from Figs. 4 and 5 that the influence of WRs on wind speed presents a strong inter-monthly variation. WRs can significantly alter average wind speed in Europe, up to $\pm 50 \%$ of its climatological value for certain WRs and months, especially from December to March (Fig. 4), as already demonstrated in the work of Grams et al. (2017).

WR influence drops considerably in April, and it is very low in May and June. It increases in July and August, even if summer months are expected to show a weaker link between large-scale circulation and local climate (Efthymiadis et al. 2007), i.e: WR impact is expected to be weaker in summer months. Such an increase of the impact in July and August is due to the definition of impact adopted in this study, as the $\%$ referred to the monthly wind speed climatology. Average wind speed is lower in summer months than in winter ones, so the $\%$ impact is higher in summer months, even if the absolute impact (in $\mathrm{m} / \mathrm{s}$ ) doesn't change.

Northern, western and southeastern Europe wind speed is often affected in a different way by WRs. The spatial impact patterns present a bipolar structure with a clear north-south gradient when wind anomalies are associated to WRs whose SLP patterns resembles the wintertime NAO+ or $\mathrm{NAO}$ - regime, as in the case of the first and fourth more frequent WRs in December (Fig. 4).

WRs determine a severe decline of wind speed over central Europe when their SLP patterns are higher than normal over Scandinavia, as for example in the second most frequent December WR, when the wind anomalies are the most negative and with the most widespread impact over Europe. On the contrary, higher than normal wind speeds over central Europe are observed in correspondence to WRs with SLP patterns similar to the one of the third more frequent WR in December (Fig. 1), which resembles the pattern of the wintertime AR regime.

Differently from SLP anomalies, wind anomalies display low pattern (spatial) correlations between pairs of different reanalyses, of 0.90 or lower for many months (even if correlations are always significant at the confidence level of $95 \%$ ), as shown by the bold numbers in Table 2 . Minimum pattern correlations values (down to $r=0.12$ ) are measured in April and July, as a consequence of the different SLP patterns generated in these months (see Sect. 3.1).

The majority of the lowest correlation values are detected when comparing NCEP to the other reanalyses, denoting the presence of a systematic bias in NCEP reanalysis. It is also evident from Table 2 that impact maps from JRA-55 and ERA-Interim are very similar (except in July), with pattern correlations of 0.93 or higher.

WRs with negative wind speed anomalies over central Europe in Figs. 4 and 5 not only are associated to higher than normal SLP anomalies over central and northern Europe (Figs. 1 and 2), but often they are also flanked by areas with positive wind speed anomalies, particularly Iberian Peninsula, the whole Balkan region (up to the Black Sea), northern Scandinavia, Iceland and the Adriatic Sea, in agreement with Grams et al. (2017).

\subsection{Reconstruction of wind speed by WRs}

Both the methodology and the spatial domain of the clustering usually determine sub-areas inside the study region where the influence of WRs on wind speed is higher or lower than the rest of the domain, and where WRs can better or worse reconstruct monthly wind speed. To understand where and when the influence of the WR classification on wind speed is high or low, and to assess its goodness in reconstructing monthly wind speed, a leave-one-out crossvalidation of the wind speed reconstructed by the four WRs was performed. Results were summarized in Fig. 6 for January, April, July and October. Results for the other months can be found in Figs. 9, 10, 11 and 12 of the supplementary material.

The correlations between observed mean wind speed and the one reconstructed by WRs are shown on the top row of Fig. 6. They are highest $(r \geq 0.5)$ in January and in northern and western Europe, particularly in England, Spain, Portugal, Denmark, in the northern part of France, Germany and Poland and in the southern part of Sweden and Norway. Similar results are found for all months from November to March. Lowest correlations are measured from April to July, particularly in Eastern Europe, North Africa, Middle East and in the Mediterranean Basin. In the North Sea, a key region for European wind power generation, correlations are often positive and in January are always above 0.5 .

The second row of Fig. 6 presents the ratio between the reconstructed and observed wind speed standard deviation. It is always lower than 0.6 , and it has a spatial distribution very similar to that of the mean wind speed correlations previously described. Values are quite low and represent the main limitation of the wind speed reconstruction.

The third row of figures illustrates the temporal correlations between observed and reconstructed 95th percentile of 
Fig. 4 Average (1981-2016) JRA-55 10-m wind speed relative anomalies (in \%) for each of the four monthly regimes from December (top row) to May (bottom row). Regimes are shown, from left to right, in decreasing order of average monthly frequency of occurrence (1981-2016), as in Fig. 1. Contour lines show associated SLP anomalies, with a separation of $2 \mathrm{hPa}$. Bold black lines show null anomalies, while dashed lines show negative ones. Black points indicate areas where anomalies are significantly different from zero (t-test at $99 \%$ confidence level)
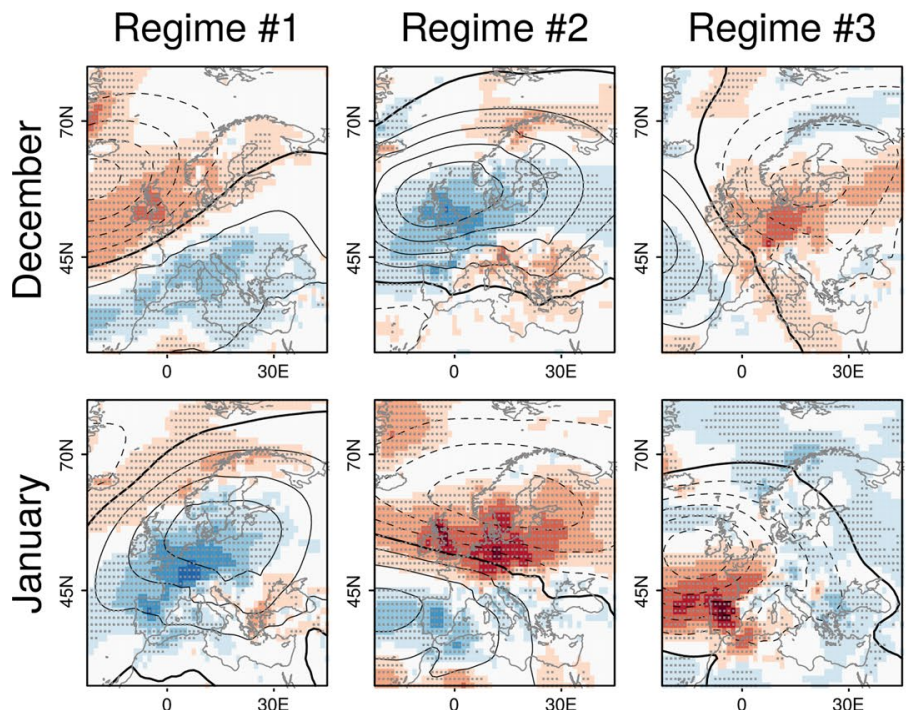

Regime \#4
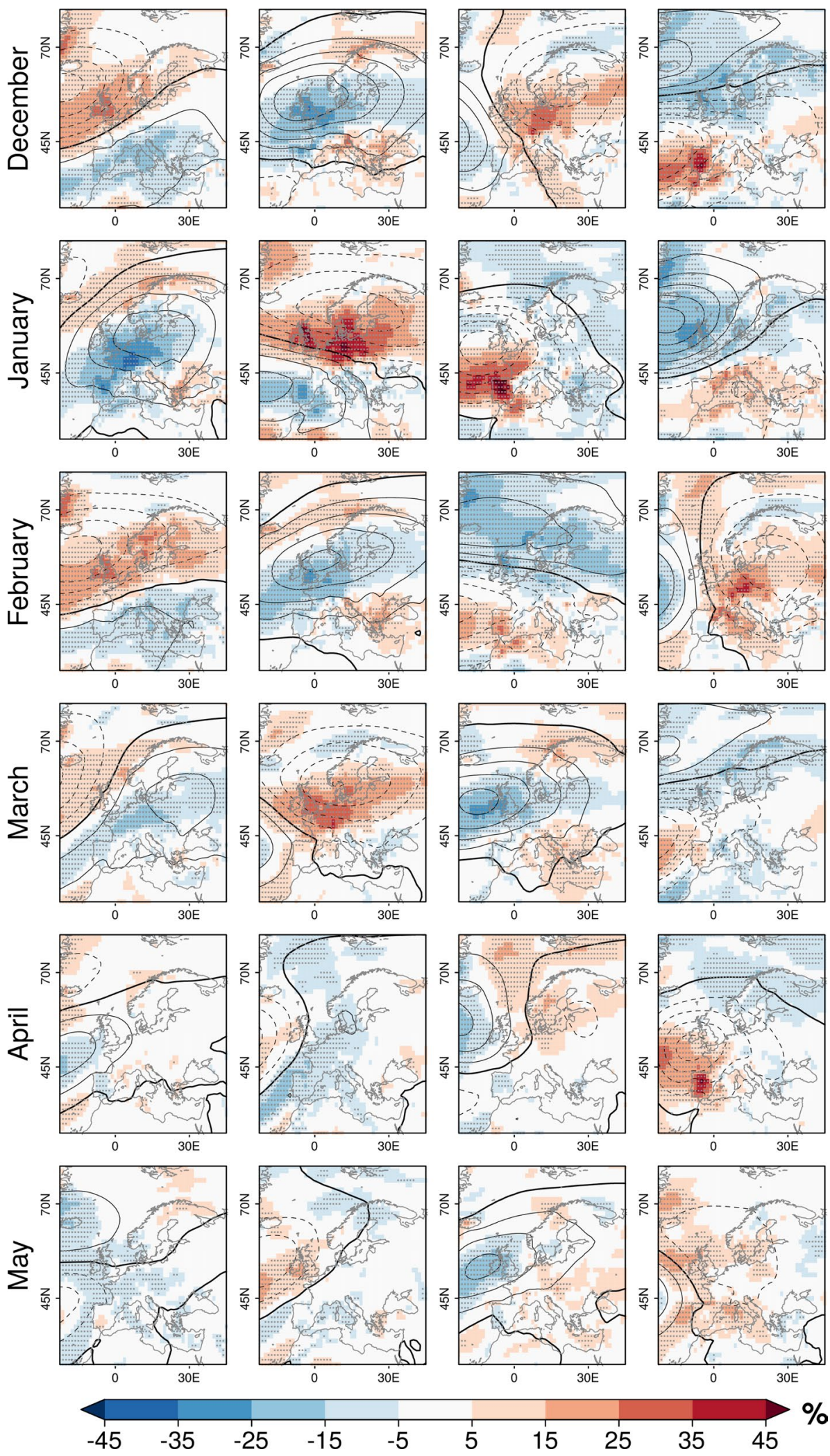
Fig. 5 As Fig. 4, but from June to November
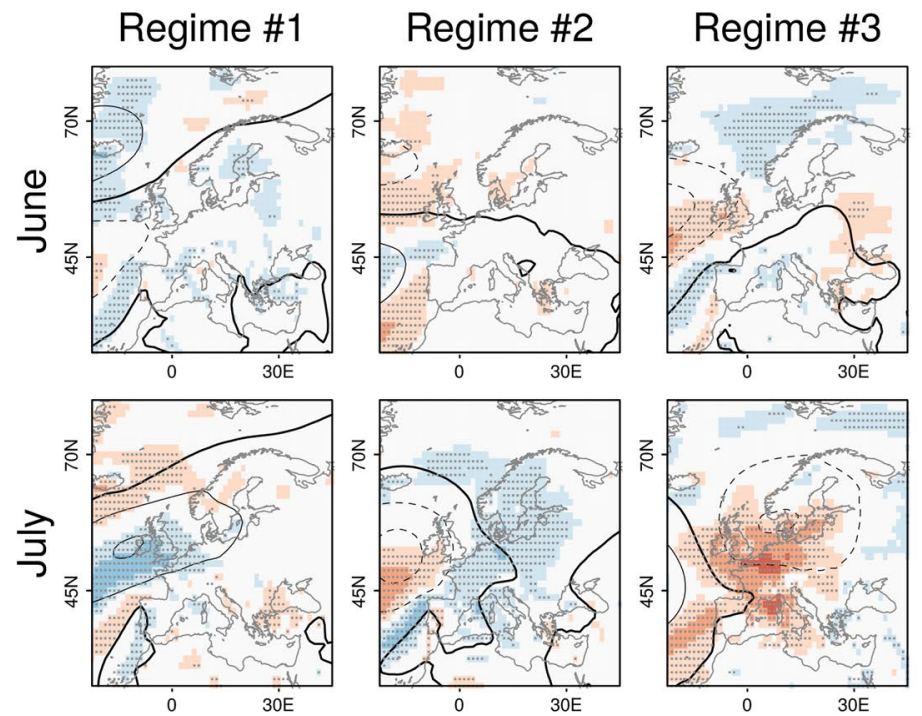

Regime \#4
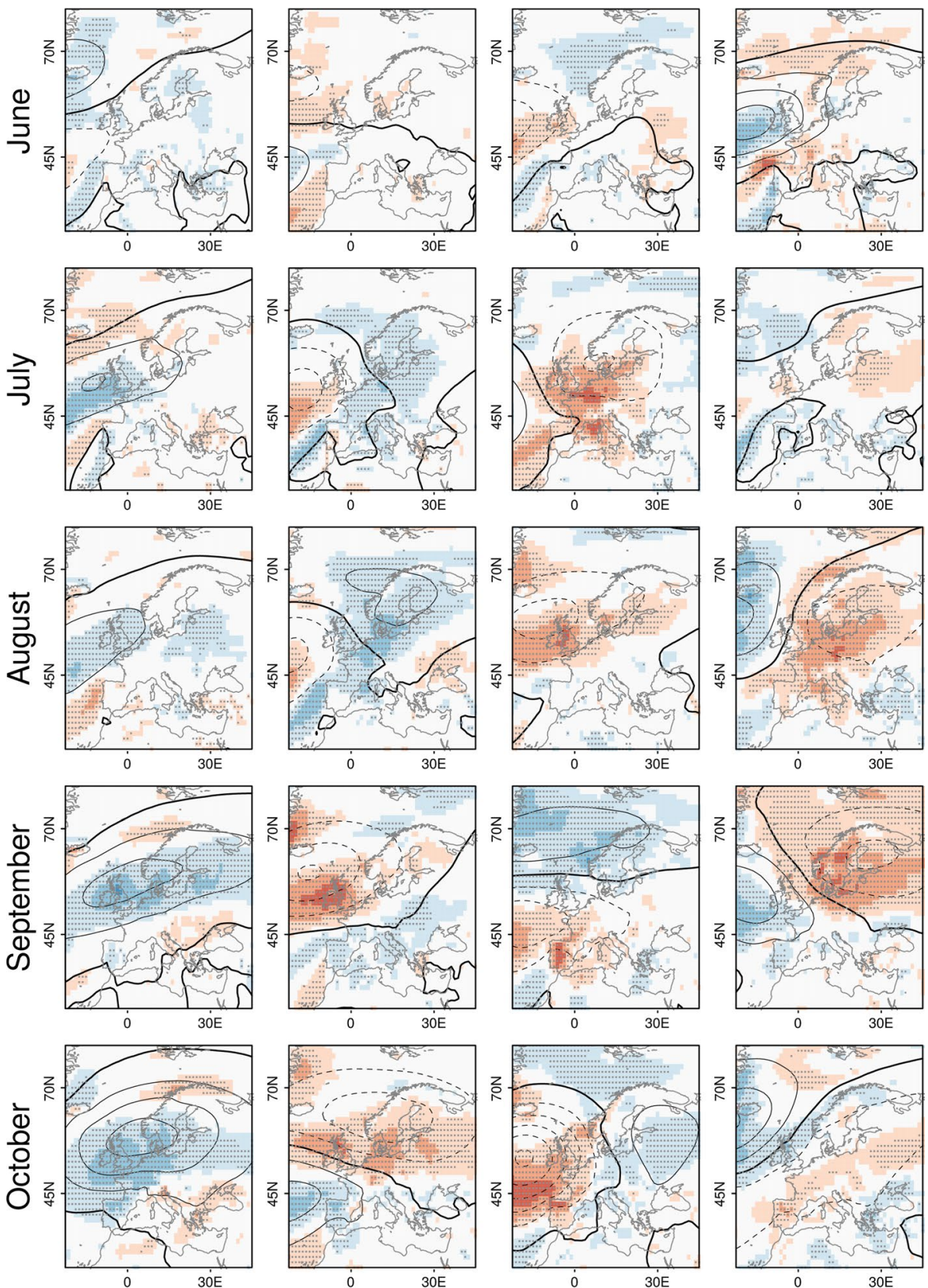

$\frac{\grave{d}}{\mathrm{E}}$
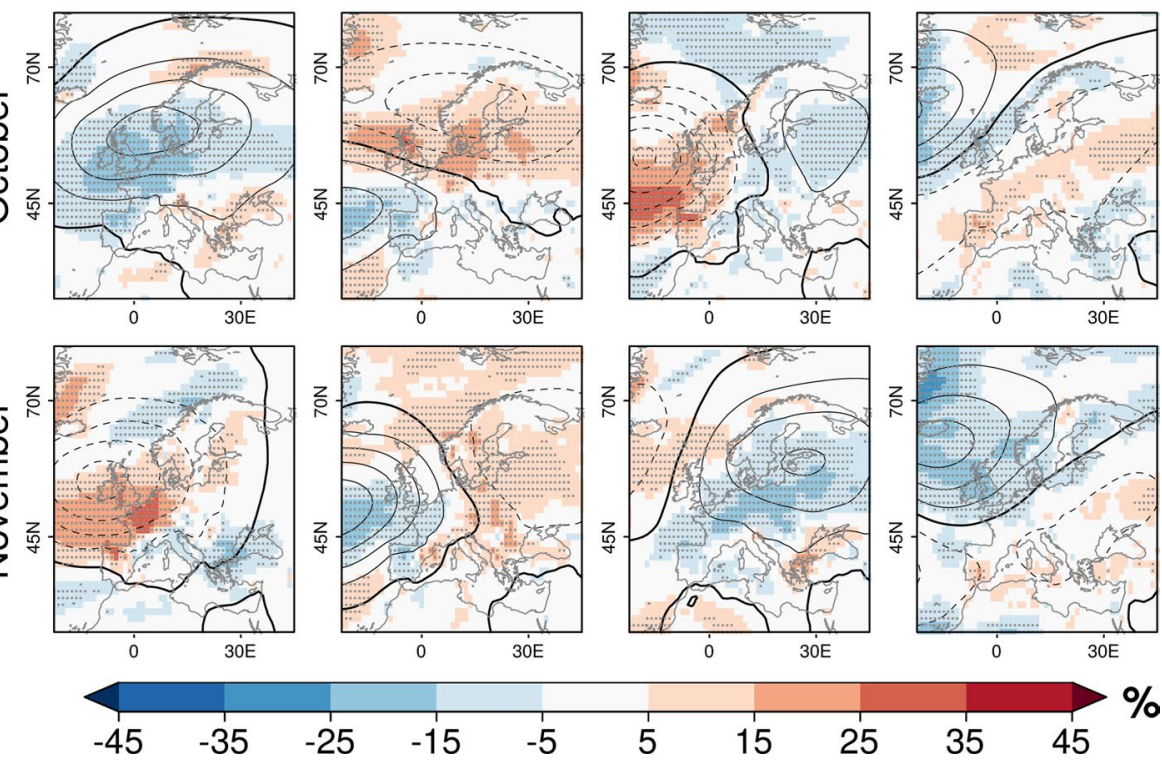

15

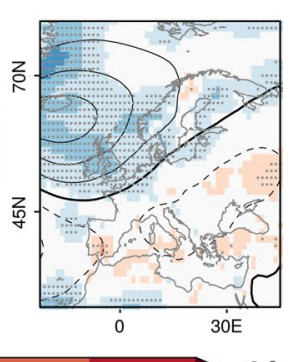

25

35 
Table 2 Pattern correlations between monthly $10-\mathrm{m}$ wind speed anomalies of the two corresponding WRs from pairs of reanalyses (JRA-55 \& ERAInterim, JRA-55 \& NCEP and ERA-Interim \& NCEP)

\begin{tabular}{|c|c|c|c|c|c|c|c|c|c|c|c|c|}
\hline \multirow[t]{2}{*}{ Month } & \multicolumn{4}{|c|}{ JRA-55 \& ERA-Interim } & \multicolumn{4}{|c|}{ JRA-55 \& NCEP } & \multicolumn{4}{|c|}{ ERA-Interim \& NCEP } \\
\hline & WR 1 & WR 2 & 3 & WR 4 & WR 1 & 2 & 3 & R 4 & WR 1 & WR 2 & WR 3 & WR \\
\hline January & 0.958 & 0.976 & 0.970 & 0.964 & 0.881 & 0.930 & 0.915 & 0.899 & 0.913 & 0.943 & 0.931 & 0.904 \\
\hline February & 0.968 & 0.958 & 0.963 & 0.955 & 0.917 & 0.858 & 0.900 & 0.891 & 0.927 & 0.883 & 0.912 & 0.902 \\
\hline March & 0.962 & 0.975 & 0.969 & 0.961 & 0.862 & 0.919 & 0.893 & 0.906 & 0.887 & 0.935 & 0.909 & 0.916 \\
\hline April & 0.963 & 0.971 & 0.962 & 0.976 & 0.540 & 0.837 & 0.693 & 0.123 & 0.537 & 0.859 & 0.699 & 0.120 \\
\hline May & 0.962 & 0.964 & 0.946 & 0.957 & 0.869 & 0.899 & 0.847 & 0.887 & 0.896 & 0.911 & 0.845 & 0.905 \\
\hline June & 0.933 & 0.966 & 0.959 & 0.943 & 0.830 & 0.904 & 0.877 & 0.856 & 0.827 & 0.907 & 0.909 & 0.866 \\
\hline July & 0.900 & 0.611 & 0.855 & 0.541 & 0.787 & 0.586 & 0.886 & 0.721 & 0.857 & 0.721 & 0.769 & 0.696 \\
\hline August & 0.957 & 0.963 & 0.967 & 0.964 & 0.879 & 0.899 & 0.902 & 0.881 & 0.886 & 0.913 & 0.922 & 0.890 \\
\hline September & 0.966 & 0.969 & 0.955 & 0.973 & 0.880 & 0.915 & 0.860 & 0.916 & 0.885 & 0.913 & 0.889 & 0.924 \\
\hline October & 0.967 & 0.969 & 0.978 & 0.958 & 0.914 & 0.886 & 0.944 & 0.864 & 0.922 & 0.908 & 0.954 & 0.871 \\
\hline November & 0.971 & 0.964 & 0.951 & 0.964 & 0.920 & 0.899 & 0.865 & 0.891 & 0.926 & 0.916 & 0.880 & 0.903 \\
\hline December & 0.973 & 0.963 & 0.963 & 0.963 & 0.912 & 0.888 & 0.896 & 0.914 & 0.928 & 0.906 & 0.907 & 0.935 \\
\hline
\end{tabular}

Bold numbers show correlations of 0.90 or lower wind speed. Their values are similar to those of the mean wind speed (first row), even though positive correlations are globally $\sim 0.1$ lower, while negative ones are globally $\sim 0.1$ higher (i.e: less negative than correlations of the first row). Finally, the mean wind speed bias is shown in the last row of Fig. 6. It is negligible over the whole European region, as it is always lower than $0.15 \%$ of mean wind speed. Moreover, the bias is never significant for a paired $t$-test with a $90 \%$ confidence level.

The more interesting feature of Fig. 6, from the point of view of wind energy generation, is that it identifies other countries beyond those closer to the North Sea where wind speed is still influenced by WRs, like the Iberian Peninsula, Iceland, northern Scandinavia and to a lesser extent the Gulf of Lion (southern France), the Black Sea and the Aegean Sea (between Greece and Turkey). In such regions, the goodness of the reconstruction during many months of the year (mean wind speed correlation of 0.3-0.6) allows to infer that a good amount of wind variability can be attributed to the change of the monthly frequencies of occurrence of the WRs, a key factor when developing tailored products for the wind energy sector.

Some of the above regions, particularly northern Scandinavia, southern Spain and the Aegean Sea, are also characterized by high average yearly wind speeds $(7-10 \mathrm{~m} / \mathrm{s})$ and are far enough from the North Sea to exhibit positive wind anomalies when they are negative over central Europe (Figs. 4, 5). Thus, they might play an important role in future electricity generation, by reducing the high intermittency of total produced European wind power.

\section{Discussion}

In this work, the WR paradigm was employed to generate a monthly WR classification, characterized by different spatial structures than those of the more commonly used seasonally- or yearly-defined WR classifications.

The number of WRs for each month was set to four, which is the optimal number of WRs employed in winter or summer season in literature (e.g. Hannachi et al. 2017). Selecting the same number of WRs for each month is convenient for many user applications, but it does not always correspond to the optimal number of WRs for the chosen month, as the intra-cluster variability increases in the transition seasons (spring and autumn months), when WR patterns show a higher variability than normal, as they relate to winter regimes in some years and to summer ones in others (Cassou 2008).

In case of JRA-55, the optimal number of WRs detected in each month was four (not shown), except in April and October, when the optimal number increases to six, based on 26 different criteria (Charrad et al. 2014). Thus, users interested in applying monthly WRs to analyse climate variability with a higher accuracy, should rely on classifications with a variable number of WRs for month, at least in the transition seasons. We are also aware that monthly regime classifications are generally less robust than seasonal or annual ones, due to the lower number of data employed in the study period. 


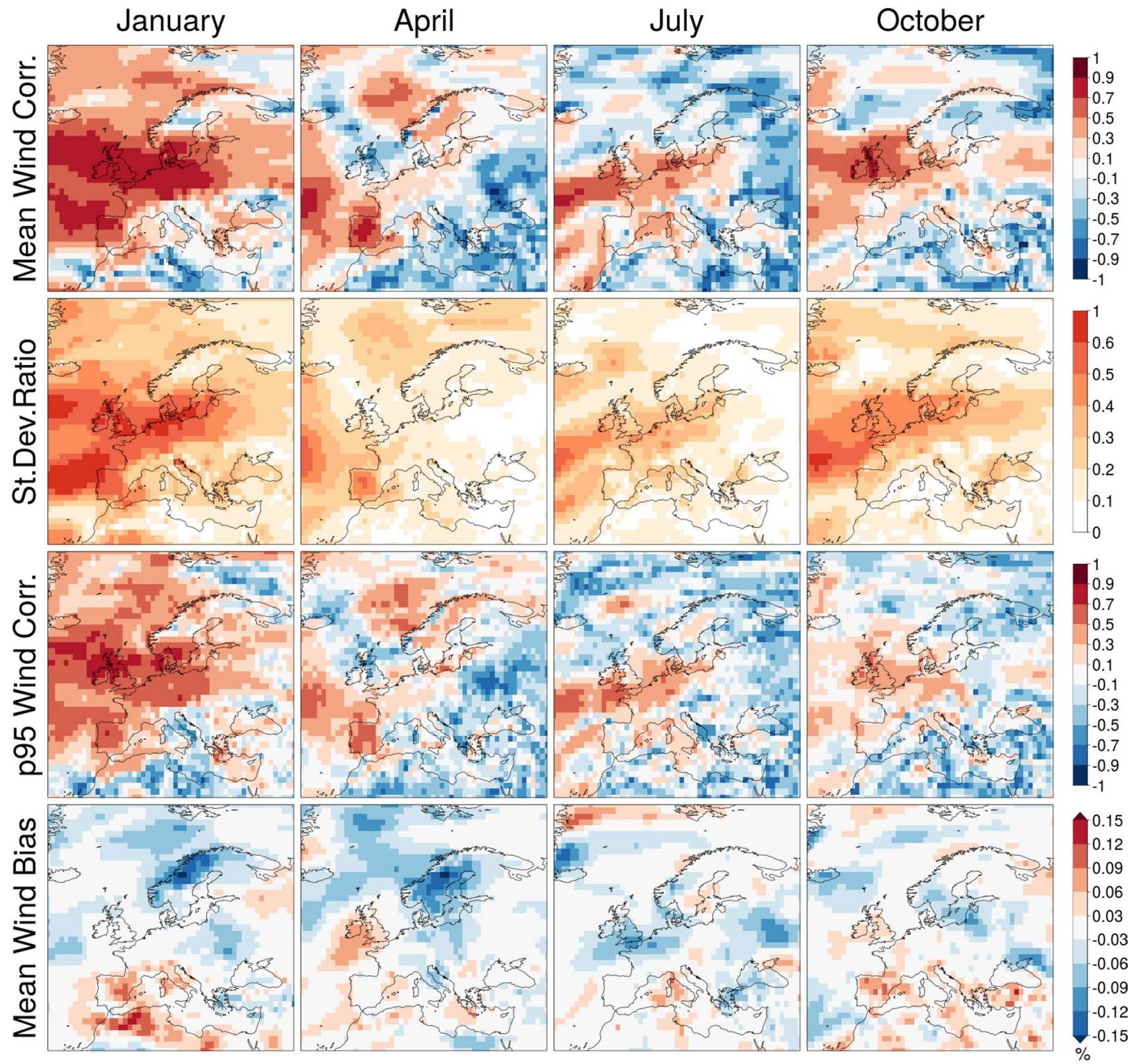

Fig. 6 Leave-one-out cross-validation of the reconstructed 10-m wind speed for the months of January, April, July and October (other months can be found in Figs. 9, 10, 11 and 12 of the supplementary material). Four error metrics are shown from top to bottom, respectively: the temporal correlation between the time series of the reconstructed and observed monthly mean wind speed anomalies, the ratio

Annual WR classifications are usually characterized by a higher number of WRs (seven or more), to decrease the intra-cluster variability (Coleman and Rogers 2007; Fereday et al. 2008). Their main advantage over the monthly ones consists in having stable regime anomalies through the year. In this way, only their frequency of occurrence and their impact on wind speed varies from one month to the next. between the standard deviations of the reconstructed and observed time series of monthly mean speed anomalies, the correlation between the reconstructed and observed monthly 95th percentile of wind speed anomalies, and the mean wind speed bias (in \%) Source JRA-55 reanalysis

The strong correspondence between the WR patterns of the three reanalyses demonstrates that changing the observational source has little or no influence on the WR classification. Therefore, the choice of one of these products for the development of climate service applications is conditioned on the frequency of update of their data.

JRA-55 shows some advantages for its use in an operational context, such as its sub-weekly update frequency and its spatial 
resolution of $1.25^{\circ}$ which makes this dataset suitable for the WR classification. However, it is not available for commercial use and it shows artificial near-surface wind speed trends (Torralba et al. 2017a). Thus, products dealing with long-term wind variability should not rely on JRA-55 reanalysis.

Recently released ERA-5 global reanalysis (https://cds. climate.copernicus.eu/cdsapp\#!/home) is an option that will be explored in future works, even if at present its data is released with a delay of 2-3 months. Regional reanalyses such as those developed in the framework of the 'Uncertainties in ensemble of Regional Reanalyses' project (UERRA, http://www.uerra.eu), instead, only cover a small part of the Northern Atlantic, so they can't be selected to classify WRs in the Euro-Atlantic region.

\section{Conclusions}

WRs represent a convenient framework to understand wind speed variability in most part of Europe, as they can have a large influence on day-to-day wind speed variations. The added value of WRs for the development of wind energy applications was investigated by validating a monthly WR classification employing three different reanalyses (NCEP, ERA-Interim and JRA-55) in the Euro-Atlantic region during 36 years (1981-2016).

This study also identified, for the first time to the best of our knowledge, in which regions and months WRs as a whole have a higher or lower impact on wind speed over Europe, by investigating their ability to reconstruct wind speed. This knowledge complements that of the impact of each single WR on wind speed and it is critical for identifying in which areas WRs can be considered sources of predictability of wind speed and effectively employed to develop user's products.

Three goals were identified, namely the reanalysis intercomparison of monthly regime patterns and frequencies, the intercomparison of the impact of WRs on observed wind speed anomalies and the reconstruction of wind speed by WRs. For each of these objectives, their main results were summarized below with bullet points.

Intercomparison of WR patterns and frequencies

- Even if most of the monthly WR patterns closely resemble winter regimes (NAO+, NAO-, blocking and Atlantic ridge), some regimes that are not present in winter or annual classifications emerge.

- Within the same reanalysis, monthly WR patterns are similar from November to March and more heterogeneous from April to October. During summer, monthly WR patterns are usually weaker than during other months.
- WR classifications between different reanalyses can be considered equivalent in most of the months. Only two exceptions were detected in July and April, when the percentage of days classified with different WRs increases up to $37 \%$, while pattern correlations drop as low as $r=$ 0.30 .

- Differences highlighted for April in the previous point disappear if SLP is interpolated before the $k$-means clustering. This is a perfect example of how results are sensitive not only to the reanalysis choice but also to the methodology employed to classify WRs (Stryhal and Huth 2017).

\section{Intercomparison of the impact of WRs on wind speed}

- The influence of WRs on wind speed drops considerably in April, and it is very low in May and June.

- As a consequence of the different WR patterns detected in April and July for some pairs of reanalyses, also wind speed anomalies associated with specific regimes are different during these months.

- The above mentioned-discrepancies were detected when comparing NCEP to the other reanalyses, which may indicate the presence of a systematic bias in NCEP's wind data.

- WR impact on wind energy resources is in agreement with the results presented by Grams et al. (2017), suggesting that they are robust and invariant to a change of reanalysis data (JRA-55 instead of ERA-Interim), methodology (the number and type of WRs) and time scale (monthly-based WRs instead of yearly-based).

\section{Wind speed reconstruction by WRs}

- Temporal correlations between observed mean wind speed and the reconstructed one are usually higher than $r=0.5$ from November to March in northern and western part of Europe.

- Lowest correlations were measured from April to July particularly in Eastern Europe, North Africa and in many other countries surrounding the Mediterranean sea.

- The wind speed reconstruction is not able to adequately reproduce the ratio between the observed and reconstructed standard deviation of wind speed, as indicated by ratio lower than 0.6 .

- The temporal correlations between observed and reconstructed 95th percentile of wind speed (very high/extreme wind speed) exhibit spatial patterns similar to those of the mean wind speed correlation, but less intense.

- The bias of the reconstructed wind speed can be considered negligible and not significant over all Europe.

- There are regions as northern Scandinavia, southern Spain and the Aegean Sea with high average yearly wind 
speed $(7-10 \mathrm{~m} / \mathrm{s})$ and where the overall influence of WRs on wind speed is moderate-to-high. Moreover, due to their distance from the North Sea, wind generation in these regions is not negatively affected by the passage of anticyclones over central Europe, where most of European wind power is concentrated. Thus, these regions might play an important role in future electricity generation, by reducing the high intermittency of total produced European wind power, as already demonstrated by Grams et al. (2017).

Concluding, it is worth noticing that many renewable energy applications require not only the historical monthly frequency of occurrence of the WRs, but also its accurate monthly or seasonal forecasting, as well as improved subseasonal predictability of wind speed (Beerli et al. 2017). Recently, it was found that WRs might have more skill than temperature or precipitation in predicting important climate indices such as droughts (Lavaysse et al. 2018), cold spells (Ferranti et al. 2018) or heat waves (Schaller et al. 2018). Similarly, future work might prove that WRs have more skill than wind in forecasting indices such as wind droughts or capacity factor, both critical variables for many renewable energy decision-making processes, particularly in those European areas where forecasts of these indices have limited skill.

Acknowledgements The research leading to these results has received funding from the Ministerio de Economía y Competitividad (MINECO) as part of the Juan de la Cierva - Incorporación Grant (IJCI-201629776), from the New European Wind Atlas (NEWA-II) project (PCIN2016-029) and from the Subseasonal to Seasonal for Energy (S2S4E) Project (GA776787). The authors would like to express their gratitude to Dr. Javier García-Serrano for his insightful comments and suggestions. We acknowledge the s2dverification R-language-based software package (Manubens et al. 2018) developers, as this package was used for the data analysis and the visualization of the results presented in this work.

Open Access This article is distributed under the terms of the Creative Commons Attribution 4.0 International License (http://creativeco mmons.org/licenses/by/4.0/), which permits unrestricted use, distribution, and reproduction in any medium, provided you give appropriate credit to the original author(s) and the source, provide a link to the Creative Commons license, and indicate if changes were made.

\section{References}

Barnston AG, Livezey RE (1987) Classification, seasonality and persistence of low-frequency atmospheric circulation patterns. Mon Weather Rev 115(6):1083-1126

Beck C, Jacobeit J, Jones P (2007) Frequency and within-type variations of large-scale circulation types and their effects on low-frequency climate variability in central Europe since 1780. Int J Climatol J R Meteorol Soc 27(4):473-491. https://doi.org/10.1002/ joc. 1410
Beerli R, Wernli H, Grams CM (2017) Does the lower stratosphere provide predictability for month-ahead wind electricity generation in Europe? Q J R Meteorol Soc 143(709):3025-3036. https://doi. $\operatorname{org} / 10.1002 / \mathrm{qj} .3158$

Boé J, Terray L, Habets F, Martin E (2007) Statistical and dynamical downscaling of the Seine basin climate for hydro-meteorological studies. Int J Clim J R Meteorol Soc 27(12):1643-1655. https:// doi.org/10.1002/joc.1602

Carvalho D, Rocha A, Gómez-Gesteira M, Santos CS (2014) Wrf wind simulation and wind energy production estimates forced by different reanalyses: comparison with observed data for Portugal. Appl Energy 117:116-126. https://doi.org/10.1016/j.renen e.2016.03.005

Casado M, Pastor M, Doblas-Reyes F (2009) Euro-Atlantic circulation types and modes of variability in winter. Theor Appl Climatol 96(1-2):17-29. https://doi.org/10.1007/s00704-008-0036-2

Cassou C (2008) Intraseasonal interaction between the MaddenJulian oscillation and the North Atlantic oscillation. Nature 455(15):523-527. https://doi.org/10.1038/nature07286

Cassou C, Terray L, Hurrell JW, Deser C (2004) North Atlantic winter climate regimes: spatial asymmetry, stationarity with time, and oceanic forcing. J Clim 17(5):1055-1068. https://doi. org/10.1175/1520-0442(2004)017

Cassou C, Terray L, Phillips AS (2005) Tropical Atlantic influence on European heat waves. J Clim 18(15):2805-2811. https://doi. org/10.1175/JCLI3506.1

Charrad M, Ghazzali N, Boiteau V, Niknafs A (2014) Determining the best number of clusters in a data set. J Stat Softw. https://doi. org/10.18637/jss.v061.i06

Coleman JS, Rogers JC (2007) A synoptic climatology of the central United States and associations with Pacific teleconnection pattern frequency. J Clim 20(14):3485-3497. https://doi.org/10.1175/ JCLI4201.1

Couto A, Costa P, Rodrigues L, Lopes VV, Estanqueiro A (2015) Impact of weather regimes on the wind power ramp forecast in Portugal. IEEE Trans Sustain Energy 6(3):934-942. https://doi. org/10.1109/TSTE.2014.2334062

Dawson A, Palmer T, Corti S (2012) Simulating regime structures in weather and climate prediction models. Geophys Res Lett. https ://doi.org/10.1029/2012GL053284

Dee DP, Uppala SM, Simmons A, Berrisford P, Poli P, Kobayashi S, Andrae U, Balmaseda M, Balsamo G, Bauer dP et al (2011) The ERA-interim reanalysis: configuration and performance of the data assimilation system. Q J R Meteorol Soc 137(656):553-597. https://doi.org/10.1002/qj.828

Dell'Aquila A, Corti S, Weisheimer A, Hersbach H, Peubey C, Poli P, Berrisford P, Dee D, Simmons A (2016) Benchmarking Northern Hemisphere midlatitude atmospheric synoptic variability in centennial reanalysis and numerical simulations. Geophys Res Lett 43(10):5442-5449

Dünkeloh A, Jacobeit J (2003) Circulation dynamics of mediterranean precipitation variability 1948-1998. Int J Clim 23(15):1843-1866. https://doi.org/10.1002/joc.973

Efthymiadis D, Jones PD, Briffa KR, Böhm R, Maugeri M (2007) Influence of large-scale atmospheric circulation on climate variability in the Greater Alpine region of Europe. J Geophys Res Atmos. https://doi.org/10.1029/2006JD008021

Esteban P, Martin-Vide J, Mases M (2006) Daily atmospheric circulation catalogue for Western Europe using multivariate techniques. Int J Clim 26(11):1501-1515. https://doi.org/10.1002/joc.1391

Fereday D (2017) How persistent are North Atlantic-European sector weather regimes? J Clim 30(7):2381-2394. https://doi. org/10.1175/JCLI-D-16-0328.1

Fereday D, Knight J, Scaife A, Folland C, Philipp A (2008) Cluster analysis of North Atlantic-European circulation types and 
links with tropical pacific sea surface temperatures. J Clim 21(15):3687-3703. https://doi.org/10.1175/2007JCLI1875.1

Ferranti L, Corti S (2011) New clustering products. ECMWF Newsl 127(6-11):1-2

Ferranti L, Corti S, Janousek M (2015) Flow-dependent verification of the ECMWF ensemble over the Euro-Atlantic sector. Q J R Meteorol Soc 141(688):916-924. https://doi.org/10.1002/qj.2411

Ferranti L, Magnusson L, Vitart F, Richardson DS (2018) How far in advance can we predict changes in large-scale flow leading to severe cold conditions over Europe? Q J R Meteorol Soc 144(715):1788-1802. https://doi.org/10.1002/qj.3341

Fil C, Dubus L (2005) Winter climate regimes over the North Atlantic and European region in ERA40 reanalysis and DEMETER seasonal hindcasts. Tellus Dyn Meteorol Oceanogr 57(3):290-307. https://doi.org/10.1111/j.1600-0870.2005.00127.x

Ghil M, Robertson AW (2002) "Waves" vs. "particles" in the atmosphere's phase space: a pathway to long-range forecasting? Proc Natl Acad Sci 99(suppl 1):2493-2500. https://doi.org/10.1073/ pnas.012580899

Gonzalez-Reviriego N, Rodriguez-Puebla C, Rodriguez-Fonseca B (2015) Evaluation of observed and simulated teleconnections over the Euro-Atlantic region on the basis of partial least squares regression. Clim Dyn 44(11-12):2989-3014. https://doi. org/10.1007/s00382-014-2367-2

Grams CM, Beerli R, Pfenninger S, Staffell I, Wernli H (2017) Balancing Europe's wind-power output through spatial deployment informed by weather regimes. Nat Clim Change Lett 7(8):557. https://doi.org/10.1038/NCLIMATE3338

Guemas V, Salas-Mélia D, Kageyama M, Giordani H, Voldoire A, Sanchez-Gomez E (2010) Summer interactions between weather regimes and surface ocean in the North-Atlantic region. Clim Dyn 34(4):527-546. https://doi.org/10.1007/s00382-008-0491-6

Hannachi A, Straus DM, Franzke CL, Corti S, Woollings T (2017) Low-frequency nonlinearity and regime behavior in the Northern Hemisphere extratropical atmosphere. Rev Geophys 55(1):199234. https://doi.org/10.1002/2015RG000509

Hartigan JA, Wong MA (1979) Algorithm as 136: a k-means clustering algorithm. J R Stat Soc Ser C Appl Stat 28(1):100-108

Hurrell JW (1996) Influence of variations in extratropical wintertime teleconnections on Northern Hemisphere temperature. Geophys Res Lett 23(6):665-668

Hurrell JW, Deser C (2009) North Atlantic climate variability: the role of the North Atlantic oscillation. J Mar Syst 78(1):28-41. https:// doi.org/10.1016/j.jmarsys.2008.11.026

Huth R, Beck C, Philipp A, Demuzere M, Ustrnul Z, Cahynová M, Kyselỳ J, Tveito OE (2008) Classifications of atmospheric circulation patterns. Ann N Y Acad Sci 1146(1):105-152. https://doi. org/10.1196/annals.1446.019

Kalnay E, Kanamitsu M, Kistler R, Collins W, Deaven D, Gandin L, Iredell M, Saha S, White G, Woollen J et al (1996) The NCEP/NCAR 40-year reanalysis project. Bull Am Meteorol Soc 77(3):437-472. https://doi.org/10.1175/1520-0477(1996)077<0437:TNYRP $>2.0 . \mathrm{CO} ; 2$

Kempton W, Pimenta FM, Veron DE, Colle BA (2010) Electric power from offshore wind via synoptic-scale interconnection. Proc Natl Acad Sci 107(16):7240-7245. https://doi.org/10.1073/pnas.09090 75107

Kobayashi S, Ota Y, Harada Y, Ebita A, Moriya M, Onoda H, Onogi K, Kamahori H, Kobayashi C, Endo H et al (2015) The JRA55 reanalysis: general specifications and basic characteristics. J Meteorol Soc Japan Ser II 93(1):5-48. https://doi.org/10.2151/ jmsj.2015-001

Kodinariya TM, Makwana PR (2013) Review on determining number of cluster in k-means clustering. Int J Adv Res Comput Sci Manag Stud 1(6):90-95
Kumar A, Zhang L, Wang W (2013) Sea surface temperature-precipitation relationship in different reanalyses. Mon Weather Rev 141(3):1118-1123. https://doi.org/10.1175/MWR-D-12-00214.1

Lavaysse C, Vogt J, Toreti A, Carrera ML, Pappenberger F (2018) On the use of weather regimes to forecast meteorological drought over europe. Nat Hazards Earth Syst Sci 18(12):3297-3309. https://doi. org/10.5194/nhess-18-3297-2018

Lorrey AM, Fauchereau NC (2018) Southwest Pacific atmospheric weather regimes: linkages to enso and extra-tropical teleconnections. Int J Clim 38(4):1893-1909. https://doi.org/10.1002/ joc.5304

Mahlstein I, Spirig C, Liniger MA, Appenzeller C (2015) Estimating daily climatologies for climate indices derived from climate model data and observations. J Geophys Res 120(7):2808-2818. https:// doi.org/10.1002/2014JD022327

Manubens N, Caron LP, Hunter A, Bellprat O, Exarchou E, Fučkar NS, Garcia-Serrano J, Massonnet F, Ménégoz M, Sicardi V et al (2018) An R package for climate forecast verification. Environ Model Soft 103:29-42. https://doi.org/10.1016/j.envso ft.2018.01.018

Marcos R, González-Reviriego N, Torralba V, Soret A, Doblas-Reyes FJ (2018) Characterization of the near surface wind speed distribution at global scale: Era-interim reanalysis and ecmwf seasonal forecasting system 4. Clim Dyn. https://doi.org/10.1007/s0038 2-018-4338-5

Michelangeli PA, Vautard R, Legras B (1995) Weather regimes: recurrence and quasi stationarity. J Atmos Sci 52(8):1237-1256. https://doi.org/10.1175/1520-0469(1995)052<1237:WRRAQ $\mathrm{S}>2.0 . \mathrm{CO} ; 2$

Neal R, Fereday D, Crocker R, Comer RE (2016) A flexible approach to defining weather patterns and their application in weather forecasting over Europe. Meteorol Apps 23(3):389-400. https://doi. org/10.1002/met.1563

Nygård T, Vihma T, Birnbaum G, Hartmann J, King J, Lachlan-Cope T, Ladkin R, Lüpkes C, Weiss A (2016) Validation of eight atmospheric reanalyses in the Antarctic Peninsula region. Q J R Metereol Soc 142(695):684-692. https://doi.org/10.1002/qj.2691

Peña-Angulo D, Trigo R, Cortesi N, González-Hidalgo J (2016) The influence of weather types on the monthly average maximum and minimum temperatures in the Iberian Peninsula. Atm Res 178:217-230. https://doi.org/10.1016/j.atmosres.2016.03.022

Philipp A, Bartholy J, Beck C, Erpicum M, Esteban P, Fettweis X, Huth R, James P, Jourdain S, Kreienkamp F et al (2010) Cost733 cat-a database of weather and circulation type classifications. Phys Chem Earth Parts A/B/C 35(9-12):360-373. https://doi. org/10.1016/j.pce.2009.12.010

Polo I, Ullmann A, Fontaine B, Losada T, Roucou P (2013) Changes in the frequency of the weather regimes over the Euro-Atlantic and Mediterranean sector and their relation to the anomalous temperatures over the Mediterranean sea. Fisica de la Tierra 25:103-121

Preisendorfer R (1988) Principal component analysis in meteorology and oceanography. Elsevier Sci Publ 17:425

Quesada B, Vautard R, Yiou P, Hirschi M, Seneviratne SI (2012) Asymmetric European summer heat predictability from wet and dry southern winters and springs. Nat Clim Change 2(10):736. https://doi.org/10.1038/nclimate1536

Raymond F, Ullmann A, Camberlin P, Oueslati B, Drobinski P (2018) Atmospheric conditions and weather regimes associated with extreme winter dry spells over the Mediterranean basin. Clim Dyn 50(11-12):4437-4453. https://doi.org/10.1007/s0038 2-017-3884-6

Robertson AW, Ghil M (1999) Large-scale weather regimes and local climate over the Western United States. J Clim 12(6):1796-1813. https://doi.org/10.1175/1520-0442(1999) 012<1796:LSWRAL > 2.0.CO;2 
Roller CD, Qian JH, Agel L, Barlow M, Moron V (2016) Winter weather regimes in the Northeast United States. J Clim 29(8):2963-2980. https://doi.org/10.1175/JCLI-D-15-0274.1

Salameh T, Drobinski P, Vrac M, Naveau P (2009) Statistical downscaling of near-surface wind over complex terrain in Southern France. Meteorol Atmos Phys 103(1-4):253-265. https://doi. org/10.1007/s00703-008-0330-7

Sanchez-Gomez E, Terray L, Joly B (2008) Intra-seasonal atmospheric variability and extreme precipitation events in the European-Mediterranean region. Geophys Res Lett. https://doi. org/10.1029/2008GL034515

Schaller N, Sillmann J, Anstey J, Fischer E, Grams C, Russo S (2018) Influence of blocking on Northern European and Western Russian heatwaves in large climate model ensembles. Environ Res Lett 13(5):054,015. https://doi.org/10.1088/1748-9326/aaba55

Stahl K, Moore RD, Mckendry IG (2006) The role of synoptic-scale circulation in the linkage between large-scale ocean-atmosphere indices and winter surface climate in British Columbia, Canada. Int J Clim 26(4):541-560. https://doi.org/10.1029/2002JD002147

Stryhal J, Huth R (2017) Classifications of winter Euro-Atlantic circulation patterns: an intercomparison of five atmospheric reanalyses. J Clim 30(19):7847-7861. https://doi.org/10.1175/ JCLI-D-17-0059.1

Thompson DW, Wallace JM (1998) The arctic oscillation signature in the wintertime geopotential height and temperature fields. Geophys Res Lett 25(9):1297-1300

Thornton HE, Scaife AA, Hoskins BJ, Brayshaw DJ (2017) The relationship between wind power, electricity demand and winter weather patterns in Great Britain. Environ Res Lett 12(6):064,017. https://doi.org/10.1088/17489326/aa69c6

Tippett MK, DelSole T, Mason SJ, Barnston AG (2008) Regressionbased methods for finding coupled patterns. J Clim 21(17):43844398. https://doi.org/10.1175/2008JCLI2150.1

Torralba V, Doblas-Reyes FJ, Gonzalez-Reviriego N (2017a) Uncertainty in recent near-surface wind speed trends: a global reanalysis intercomparison. Environ Res Lett 12(11):114,019. https://doi. org/10.1088/1748-9326/aa8a58

Torralba V, Doblas-Reyes FJ, MacLeod D, Christel I, Davis M (2017b) Seasonal climate prediction: a new source of information for the management of wind energy resources. J App Meteorol Clim 56(5):1231-1247. https://doi.org/10.1175/JAMC-D-16-0204.1
Trigo RM, Pozo-Vázquez D, Osborn TJ, Castro-Díez Y, Gámiz-Fortis S, Esteban-Parra MJ (2004) North Atlantic oscillation influence on precipitation, river flow and water resources in the Iberian Peninsula. Int J Clim 24(8):925-944. https://doi.org/10.1002/joc.1048

Tyrlis E, Hoskins B (2008) Aspects of a Northern Hemisphere atmospheric blocking climatology. J Atmos Sci 65(5):1638-1652. https ://doi.org/10.1175/2007JAS2337.1

Vigaud N, Robertson AW, Tippett MK (2018) Predictability of recurrent weather regimes over North America during winter from submonthly reforecasts. Mon Weather Rev 146(8):2559-2577. https ://doi.org/10.1175/MWR-D-18-0058.1

Vrac M, Ayar PV, Yiou P (2014) Trends and variability of seasonal weather regimes. Int J Clim 34(2):472-480. https://doi. org/10.1002/joc. 3700

Wallace JM, Gutzler DS (1981) Teleconnections in the geopotential height field during the Northern Hemisphere winter. Mon Weather Rev 109(4):784-812. https://doi.org/10.1175/15200493(1981)109<0784:TITGHF>2.0.CO

Wilson L, Manton M, Siems S (2013) Relationship between rainfall and weather regimes in south-eastern Queensland, Australia. Int J Clim 33(4):979-991. https://doi.org/10.1002/joc.3484

Yiou P, Nogaj M (2004) Extreme climatic events and weather regimes over the North Atlantic: when and where? Geophys Res Lett. https ://doi.org/10.5194/npg-15-365-2008

Yiou P, Goubanova K, Li Z, Nogaj M (2008) Weather regime dependence of extreme value statistics for summer temperature and precipitation. Nonlin Process Geophy 15(3):365-378. https://doi. org/10.5194/npg-15-365-2008

Zubiate L, McDermott F, Sweeny C, O’Malley M (2017) Spatial variability in winter NAO-wind speed relationships in western Europe linked to concomitant states of the East Atlantic and Scandinavian patterns. Q J R Meteorol Soc 143(1):552-564. https://doi. org/10.1002/qj.2493

Publisher's Note Springer Nature remains neutral with regard to jurisdictional claims in published maps and institutional affiliations. 